УДК 902.01 https://doi.org/10.24852/2587-6112.2021.2.170.174

\title{
МЕЧИ И КИНЖАЛЫ С КОЛЬЦЕВИДНЫМ НАВЕРШИЕМ: СЛУЧАЙНЫЕ НАХОДКИ С ТЕРРИТОРИИ ЮЖНОГО ПРИУРАЛЬЯ
}

\section{(C) 2021 г. С.Ю. Николаев}

На основании выборки т.н. «случайных» находок сарматского клинкового оружия с кольцевидным навершием с территории Южного Приуралья выделяются основные их элементы (форма и сечение навершия, перекрестия, рукояти и клинка). Дается обоснование выбора «случайных» находок в качестве основы для анализа, т.к. их хорошая сохранность, в отличии от мечей и кинжалов из погребальных комплексов, позволяет лучше зафиксировать их основные элементы. В ходе исследования каждый элемент разбивается на типы в соответствии с конструктивными особенностями. Приводится анализ полученных результатов, выделяются группы мечей и кинжалов со сходным комплексом элементов, в том числе экземпляры, несущие в себе признаки как классических мечей с кольцевидным навершием, так и предшествовавшего им классического прохоровского типа. Отмечается наличие среди известных образцов «случайных» находок тупиковых (экспериментальных) линий развития отдельных элементов, что подтверждает процесс эволюции клинкового оружия ранних кочевников на данной территории. Делается вывод об эволюционном переходе прохоровских мечей и кинжалов в кольцевидные на территории Южного Приуралья и о необходимости уточнения сложившейся типологии сарматского оружия с учетом полученных данных и вновь выявленных экземпляров.

Ключевые слова: археология, сарматы, мечи и кинжалы с кольцевидным навершием, случайные находки, Южное Приуралье.

\section{SWORDS AND DAGGERS WITH RING POMMELS: ACCIDENTAL FINDS FROM THE TERRITORY OF THE SOUTHERN CIS-URALS}

\section{S. Yu. Nikolaev}

Based on a sample collection of the so-called "accidental" finds of Sarmatian bladed weapons with a ringshaped pommel from the territory of the Southern Urals, their main elements were distinguished (the shape and cross-section of the pommel, cross-guard, handle and blade). The justification for the selection of "random" finds as a basis for the analysis is provided, since their good preservation, in contrast to the swords and daggers from the burial complexes, makes it possible to better ascertain their main elements. During the study, each element is broken down into types according to the design features. An analysis of the obtained results is provided, groups of swords and daggers with a similar complex of elements were distinguished, including specimen bearing the features of both classical swords with a ring-shaped pommel and the classical preceding Prokhorovka type. The presence among the known samples of "accidental" finds of discontinuing (experimental) lines of development of individual elements was noted, which confirms the process of evolution of blade weapons of the early nomads in this territory. A conclusion is made concerning the evolutionary transition of Prokhorovka swords and daggers into ring-shaped items in the territory of the Southern Urals, and the need to clarify the existing typology of Sarmatian weapons with due account of the obtained information and newly identified specimens.

Keywords: archaeology, the Sarmatians, swords and daggers with a ring-shaped pommel, accidental finds, Southern Cis-Urals.

Создание типологического ряда тех или иных ключевых предметов материальной культуры народов прошлого является важнейшим элементом в исследовании как самих объектов, так и этих народов, в том числе кочевников Евразийской степи в эпоху раннего железа. Не является исключением и такой важнейший элемент в их материальной культуре, как клинковое оружие.

При решении вопроса о типологии клинкового оружия кочевников Евразийской степи эпохи раннего железа в качестве базового элемента традиционно выбиралось навершие. Именно на основании форм наверший исследователи классифицировали мечи и кинжалы (А.И. Мелюкова, К.Ф. Смирнов, А.М. Хазанов, М.Г. Мошкова, А.С. Скрипкин, Р.Б. Исмагилов и др.). Описывались и другие элементы оружия, в первую очередь перекрестья, а также формы и сечения клинка и рукояти, однако они отмечались как особенности конкретного образца и фактически не влияли на типологические построения. 
На этом же основании традиционно выделяется и тип меча и кинжала с кольцевидным навершием. А.М. Хазанов прямо указывал, что «из всех типов сарматских мечей мечи, а также кинжалы с кольцевым навершием являются наиболее однообразными как по форме, так и по технике изготовления ...» (Хазанов, 1971, с. 5). Описывая далее формы и особенности элементов мечей и кинжалов, автор отмечал определенное их разнообразие, сразу оговариваясь, что отличающиеся от стандартной схемы элементы малочисленны и не показательны. Из 170 проанализированных им образцов (при этом учтено всего 7 из числа «случайных» находок) подавляющее большинство описываются как короткие кинжалы длиной от 30 до 60 см, клинки двухлезвийные, линзовидные, двояковыпуклые или уплощенные в сечении, рукояти прямые, в сечении линзовидные, овальные или квадратно-прямоугольные, навершие кольцевидное, изготовлено отдельно и приварено к рукояти. В качестве редких исключений А.М. Хазанов указывает большую длину меча (свыше 60-70 см), вытянуто-треугольную форму клинка, его ромбовидное сечение с продольным ребром, также ромбовидное сечение рукояти, т.е. элементы, свойственные оружию более раннего, прохоровского типа.

В последующих исследованиях по теме клинкового оружия с кольцевидным навершием исследователи, также выделяя разнообразие форм отдельных элементов, во главу угла ставят именно навершие (Горбунов, Исмагилов, 1976; Обыденнов, Савельев, 1994; Симоненко, 2010; Таиров, 2015; Фризен, Яблонский, 2017).

К сегодняшнему дню число обнаруженных мечей и кинжалов с кольцевидным навершием как в погребальных комплексах, так и вне их (т.н. «случайных» (Савельев, 2016), многократно возросло. При этом на «случайные» находки клинкового оружия в течении длительного времени особого внимания не обращалось. Они фиксировались, но, в связи с отсутствием сопровождающего материала, не могли быть точно продатированы. Однако, их хорошая сохранность, в отличии от найденных в погребальных комплексах, позволяет точно понять особенности форм и сечений отдельных элементов. Это выгодно отличает их от мечей и кинжалов из погребальных комплексов именно с точки зрения построения типологии.

Большинство из опубликованных на настоящий момент т.н. «случайных» находок мечей и кинжалов происходит с территории Южного Приуралья - всего 218 (Савельев, 2016; Таиров, 2018; Николаев, 2019; Савельев, Николаев, 2019). Среди них 48 с кольцевидным навершием, что дает достаточно представительную выборку, позволяющую сделать четкие и обоснованные выводы. При анализе данной выборки (Горбунов, Исмагилов, 1976; Обыденнов, Савельев, 1994; Исмагилов, 2001; Таиров, 2015; Николаев, 2019; Савельев, Николаев, 2019) учитывались формы навершия, перекрестья и клинка, сечения рукояти и клинка. Различные утраты конструктивных элементов также просчитаны и не учитываются при определении процентных соотношений (табл. №1).

1. Форма навершия. Определена у 43 образцов:

1.1. кольцо - 10 экз. $(23,2 \%)$;

1.2. эллипс (горизонтальный овал) - 12 экз. $(27,9 \%)$

1.3. разомкнутое кольцо - 21 экз. (48,8\%).

У 5 экземпляров $(10,5 \%)$ навершие сохранилось частично и позволяет говорить лишь о его кольцевидной форме, без точной детализации.

2. Сечение рукояти:

2.1. ромб - 12 экз. (25\%);

2.2. уплощенный ромб - 8 экз. $(16,6 \%)$;

2.3. прямоугольник - 21 экз. (43,7\%);

2.4. уплощенный прямоугольник - 5 экз. $(10,5 \%)$;

2.5. двутавровое - 2 экз. (4,2\%).

3. Форма клинка. Выявлена у 46 образцов:

3.1. вытянуто-треугольная - 25 экз. (54,3\%);

3.2. с параллельными лезвиями и резким сужением у острия - 17 экз. (36,9\%);

3.3. с параллельными лезвиями до середины клинка, переходящими в треугольник -4 эКз. $(8,7 \%)$.

4. Сечение клинка:

4.1. линза - 5 экз. $(10,4 \%)$;

4.2. ромб - 28 экз. $(58,3 \%)$;

4.3. ромб с одним или двумя прорезанными долами - 12 экз. (25\%);

4.4. линза с прокованными долами - 1 экз. $(3,1 \%)$;

4.5. шестигранник - 2 экз. (4,2\%).

5. Форма перекрестья. Сохранилось у 38 образцов. Все перекрестья брусковидные.

5.1. массивное - 24 экз. $(63,2 \%)$;

5.2. тонкое - 14 экз. $(36,8 \%)$.

В 10 случаях $(20,8 \%)$ перекрестье утеряно.

Проведенный анализ показывает большое разнообразие элементов клинкового оружия с кольцевидным навершием - в первую очередь 
Таблица. 1.

Формы и сечения основных элементов мечей и кинжалов с кольцевидным навершием

Table. 1.

Shapes and cross-sections of the main elements of swords and daggers with a ring-shaped pommel

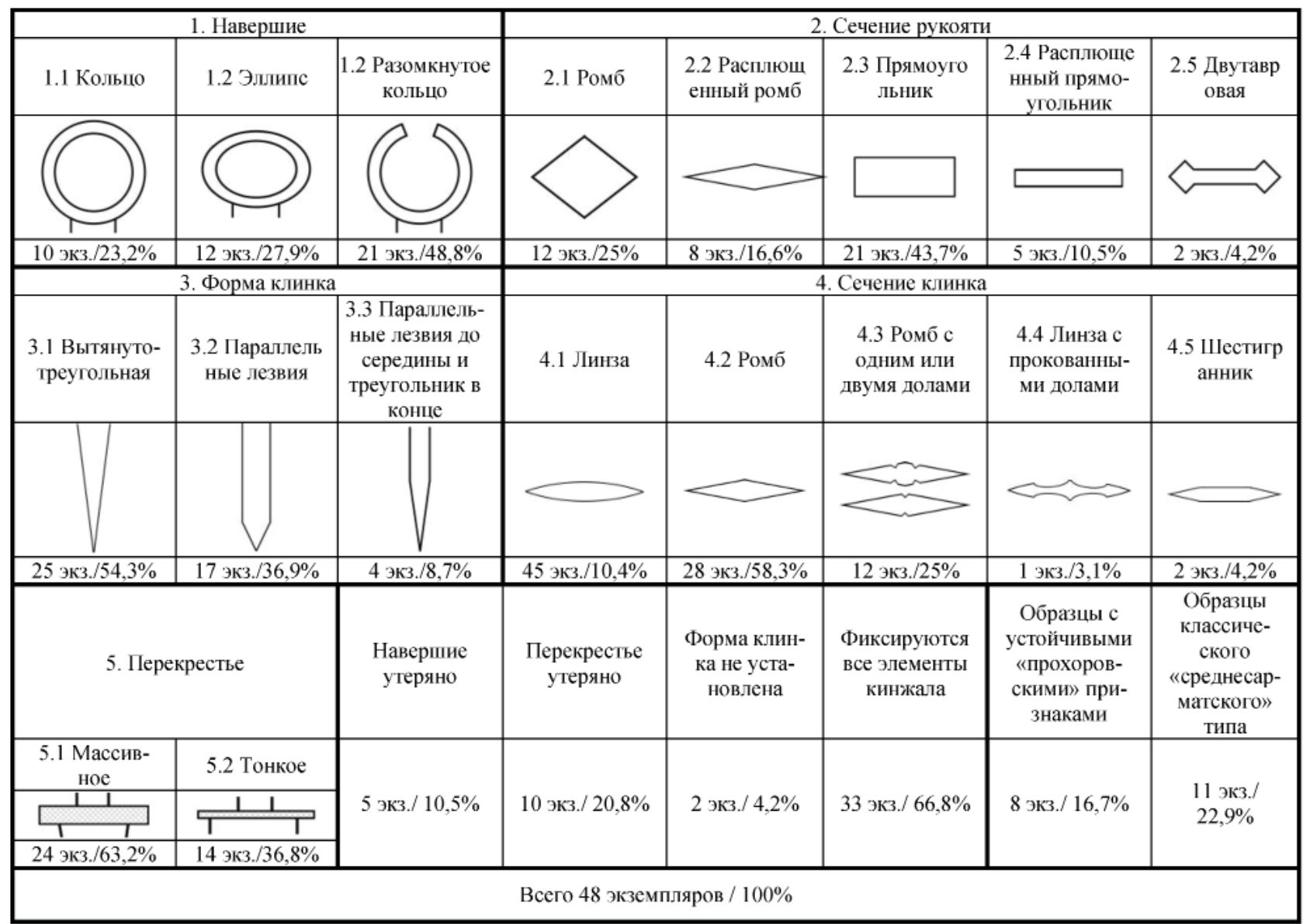

выделяются 2 группы: 1 - с клинком вытянуто-треугольной формы с сечением в виде простого ромба либо ромба с прорезанными долами, массивным перекрестьем и рукоятью с ромбовидным или прямоугольным сечением. Вторая большая группа включает в себя образцы с клинком с параллельными лезвиями, сходящимися на острие, линзовидным в сечении, рукоятью в виде уплощенных прямоугольника или ромба и тонким перекрестьем. При этом, ромбовидное сечение клинка часто встречается и во второй группе. Следует также отметить, что, если навершие в виде целого, замкнутого кольца равномерно распределено по обеим группам, то разомкнутое кольцо свойственно исключительно группе с признаками раннесарматского типа. Обращает на себя внимание большое количество признаков, свойственных мечам и кинжалам с серповидным навершием - ромбовидные сечения рукояти и клинка, массивное перекрестье, вытянуто-треугольная форма клинка (Мошкова, 1963, с. 34). В тоже время, признаки сложившегося типа меча с кольцевидным навершием (уплощенные прямоугольник или ромб в сечении рукояти, тонкое перекрестье, линзовидное сечение клинка с параллельными лезвиями и резким сужением у острия (Хазанов, 1971, с. 5), представлены меньшим количеством. При этом многие образцы несут в себе признаки обоих, совершенно различных по элементам и внешнему облику, типов - как с серповидным, так и кольцевидным навершиями. Это, в первую очередь, уже отмеченное выше большое количество ромбовидных в сечении клинков (58\% во всей выборке), которые фиксируются на кинжалах, по остальным признакам относящимся к типу с кольцевидным навершием (тонкое перекрестье, уплощенная в сечении рукоять, форма клинка с параллельными лезвиями по всей длине, собственно форма навершия). В 3 случаях с классическими для оружия с кольцевидным навершием признаками соседствует массивное перекрестье, в 5-ти - вытянутотреугольная форма клинка. Из всей выборки у 11 кинжалов (22,9\%) присутствуют признаки только классического «среднесарматского» 
оружия (с учетом экземпляров с навершием в виде разомкнутого кольца и ромбовидным сечением клинка). В то же время, кинжалов c устойчивыми «прохоровскими» признаками среди анализируемой выборки -8 экз. $(16,7 \%)$.

Анализ приведенной выборки показывает процесс эволюции клинкового оружия ранних кочевников на территории Южного Приуралья. Наблюдаются явные переходные типы, «эксперименты», постепенный переход от классического прохоровского типа меча или кинжала к т.н. «среднесарматскому», с кольцевидным навершием, которое появляется на территории Южного Приуралья как один из его (навершия) вариантов с сохранением классического «прохоровского» облика других элементов. Вместе с этим идет изме- нение и других элементов, приведшее в итоге к формированию типа клинкового оружия, известного в настоящее время как «среднесарматский». При этом следует отметить и наличие ряда тупиковых линий, экспериментов, появлявшихся в ходе процесса стандартизации, таких, как гипертрофированно-удлиненных антенн навершия, валютообразных наверший и т.д. (Исмагилов, 2001; Савельев, Николаев, 2019; Николаев, 2019).

Данный факт говорит о том, что общая типология сарматского клинкового оружия, как с серповидным, так и с кольцевидным навершием, а также устоявшиеся эволюционные построения, требуют дальнейшей детализации и уточнения на основе учета всех конструктивных элементов всей имеющейся выборки клинкового оружия.

\section{ЛИТЕРАТУРА}

Горбунов В.С., Исмагилов Р.Б. Новые находки мечей и кинжалов савромато-сарматского времени в Башкирии // СА. 1976. №3. С. 229-247.

Исмагилов Р.Б. Клинковое оружие эпохи ранних кочевников из Южного Приуралья (случайные находки) // УАВ. Вып. 3 / Отв. ред. В.К. Федоров. Уфа: НМ РБ, 2001. С. 117-147.

Мошкова М.Г. Памятники прохоровской культуры / САИ. Вып. Д1-10. М.: АН СССР, 1963. 56 с + 32 табл.

Николаев С.Ю. Комплекс сарматского клинкового оружия из окрестностей сел Куезбашево и Бишкаин в Южном Приуралье // УАВ. 2019. №. 19. С. 69-77.

Обыденнов М.Ф., Савельев Н.С. Оружие ранних кочевников: новые находки в Башкортостане // Вооружение и военное дело древних племен Южного Урала / Отв. ред. В.С. Горбунов. Уфа: ПКФ «Конкорд-Инвест, 1994. С. 100-115.

Савельев Н.С. Мечи и кинжалы в культовой практике кочевников Южного Приуралья скифо-сарматского времени (пространственный анализ «случайных» находок) // Константин Федорович Смирнов и современные проблемы сарматской археологии. / Отв. ред. Л.Т. Яблонский, Л.А. Краева. Оренбург: Изд-во ОГПУ, 2016. С. 241-253.

Савельев Н.С., Николаев С.Ю. Комплекс сарматских кинжалов из окрестностей села Толбазы в Южном Приуралье // НАВ. 2020. Т. 19. №1. С. 149-166

Симоненко A.B. Сарматские всадники Северного Причерноморья. Saint Petersburg: Нестор-История, $2010.328 \mathrm{c.}$

Скрипкин А.С. Азиатская Сарматия. Проблемы хронологии и ее исторический аспект. Саратов: Изд-во Саратовского ун-та, 1990. 300 с.

Таиров А.Д. Кинжалы с кольцевым навершием из Миякинского района республики Башкортостан // Наука ЮУрГУ. Секции социально-гуманитарных наук: материалы 67-й науч. конф. / Отв. ред. С. Д. Ваулин. Челябинск: Издательский центр ЮУрГУ, 2015. С. 516-520.

Фризен О.И., Яблонский Л.Т. Клинковое оружие ранних кочевников Южного Приуралья: культурнохронологический аспект // История оружия и военного дела. №1/2017. Часть 1. Эпоха раннего железного века / Отв. ред. В.Ю. Мурзин. Київ: Видавець Олег Філюк, 2017. С. 101-114.

Хазанов А.М. Очерки военного дела сарматов. М.: Наука, 1971. 169 с.

\section{Информация об авторе:}

Николаев Сергей Юрьевич, младший научный сотрудник отдела археологических исследований Института истории, языка и литературы Уфимского федерального исследовательского центра Российской академии наук (ИИЯЛ УФИЦ РАН) (г. Уфа, Россия); nikolaev.sergey123@yandex.ru

\section{REFERENCES}

Gorbunov, V .S., Ismagilov, R. B. 1976. In Sovetskaya arkheologiya (Soviet archeology). (3). $229-247$ (in Russian).

Ismagilov, R. B. 2001. In Fedorov, V. K. (ed.) Ufimskiy arkheologicheskiy vestnik (Ufa Archaeological Bulletin) 3. Ufa: National Museum of the Bashkir Republic, 117-147 (in Russian). 
Moshkova, M. G. 1963. Pamiatniki prokhorovskoi kul'tury (Monuments of the Prokhorovka culture). Series: Svod Arkheologicheskikh Istochnikov (Corpus of Archaeological Sources) D1-10. Moscow: Academy of Sciences of the USSR (in Russian).

Nikolaev, S. Yu. 2019. Ufimskii arkheologicheskii vestnik (Ufa Archaeological Herald) (19), 69-77 (in Russian).

Obydennov, M. F., Savel'ev, N. S. 1994. In Gorbunov, V. S. (ed.). Vooruzhenie $i$ voennoe delo drevnikh plemen Iuzhnogo Urala (Armament and Military Art of the Ancient Tribes of the Southern Urals). Ufa: "PFK "Konkord-Invest" Publ., 100-115 (in Russian).

Savelev, N. S. 2016. In Yablonsky, L. T., Kraeva, L. A. (eds.). Konstantin Fedorovich Smirnovi sovremennye problemy sarmatskoi arkheologii (Konstantin Fedorovich Smirnov and the Contemporary Issues of Sarmatian Archaeology). Orenburg: Orenburg State Pedagogical University, 241-253 (in Russian).

Savelev, N. S., Nikolaev, S. Yu. 2020. In Nizhnevolzhskii arkheologicheskii vestnik (Lower Volga Archaeological Bulletin) 19 (1), 149-166 (in Russian).

Simonenko, A. V. 2010. Sarmatskie vsadniki Severnogo Prichernomor'ia (Sarmatian Riders of the Northern Black Sea Region). Saint Petersburg: "Nestor-Istoriia" Publ. (in Russian).

Skripkin, A. S. 1990. Aziatskaia Sarmatiia (problemy khronologii i ee istoricheskii aspekt) (Sarmatia Asiatica: Issues of Chronology and Its Historical Aspect). Saratov: Saratov University (in Russian).

Tairov, A. D. 2015. In Vaulin, S. D. (ed.). Nauka Iuzhno-Uralskogo Gosudarstvennogo universiteta (Science of South Ural State University). Chelyabinsk: South Ural State University, 516-520 (in Russian).

Frizen, O. I., Yablonsky, L. T. 2017. In Murzin, V. Yu. (ed.). Istoriia oruzhiia i voennogo dela. Chast 1. Epokha rannego zheleza veka (History of Armament and Military Art. Part 1. Early Iron Age) 1. Kiev: "Vidavets Oleg Filyuk" Publ., 101-114 (in Russian).

Khazanov, A. M. 1971. Ocherki voennogo dela sarmatov (Essays on Sarmatian Warfare). Moscow: "Nauka" Publ. (in Russian).

\section{About the Author:}

Nikolaev Sergey Yu. Institute for History, Language and Literature, Ufa Federal Research Center, Russian Academy of Sciences (IHLL UFRC RAS). Oktyabrya Av., 721, Ufa, 450054, the Republic of Bashkortostan, Russian Federation; nikolaev.sergey123@yandex.ru 